\title{
A B-S Model for Online Integrated Information System for Bayero University Kano Nigeria
}

\author{
Abubakar Sulaiman Gezawa ${ }^{1}$, Ahmed Aliyu ${ }^{2}$, Abduarra'uf Garba ${ }^{3}$, Saifullahi \\ Aminu Bello ${ }^{4}$, Usman Joda ${ }^{5}$ \\ ${ }^{I}$ (System Analyst, MIS Department, Bayero University Kano, Kano, Nigeria) \\ ${ }^{2}$ (Lecturer, Department of Computer Science, Bauchi State University, Bauchi, Nigeria) \\ ${ }^{3}$ (Lecturer, Department of Computer Science, Northwest University, Kano, Nigeria) \\ ${ }^{4}$ (Lecturer, Department of Computer science, Kano University of Science and Technology, Kano, Nigeria) \\ ${ }^{5}$ (Lecturer, Department of Computer Science, Bauchi State University, Bauchi, Nigeria)
}

\begin{abstract}
An online integrated information system for Bayero University Kano, is a web-based application that provides inputs and outputs information support to admin/users in order to access and update university student record. Bayero University Kano is one of the most recognized conventional universities in Nigeria with a large number of students both undergraduate and post graduate. Papers and pens is the usual method use in student registration and record which is time consuming and waste of resources. In view of the availability of new technologies, this paper mainly concentrates on improving the manual methods by adopting a Browser Server structure which was used to design an online integrated information system for Bayero University Kano. The entire application was developed in java myeclipse environment using servlets and java server pages (JSP) technologies and SQL 2005 serve as the database backend. The system designed was generally accepted and it has proven it is importance in academic usage.
\end{abstract}

Keywords: Application, Information, student record, programming, Server, HTTP, Web browser.

\section{Introduction}

The tangible advantages of computer use in terms of efficiency and effectiveness have led to the wide utilization of computer technology for the operation and management of school organizations [1]. Information Technology in Educational Management (ITEM) is rapidly increasing in importance world-wide and is becoming an enterprise of importance in its own right. The need for keeping records about the school in general and the student(s) in particular is imperative. This can be challenging especially when manual methods are employed. This is due to referential un-integrity, space consumption, un-accessibility and unavailability.

This web base application tends to address all these problems by providing a web base platform were schools can keep records about the school and the student(s) these records are but not limited to

- Academic records

- Staff records

- Attendance records

\section{Review Of Related Works}

In 1991 the Journal of Research on Computing in Education (JRCE) published a special issue on the state of the art of computer-assisted school administration and management [1]. The special issue was meant to document, on an international level, the status of computer usage in support of school administration and management. The objective was to look at points of commonality and difference across seven countries (Australia, Hong Kong, Israel, Mexico, The Netherlands, United Kingdom, and U.S.A.) with regard to the processes and uses of computing in school administration and management. The current status and developments in the seven countries were analyzed with respect to three major issues[1]:

- The developmental stages through which computer-assisted school administration and Management had progressed;

- The available computer applications; and

- The experiences with regard to design strategies, system qualities, factors influencing implementation, and the impact of School information systems (SISs)

The importance of ITEM has increased rapidly since that special issue is shown by the enormous sums of money invested so that educational institutions may benefit from the capability of computerized information systems to support clerical work and management activities, and ultimately improve the quality of learning and teaching. Hong Kong, for example, invests 70 million US dollars to develop an 
integrated computer network linking the Education department and more than 1,500 primary and secondary schools.

\subsection{Java Server-Side Programming (Java Servlets)}

According to [2] Java servlets are server-side programs (running inside a web server) that handle clients' requests and return a customized or dynamic response for each request. The dynamic response could be based on user's input (e.g., search, online shopping, online transaction) with data retrieved from databases or other applications, or time-sensitive data (such as news). Java servlets typically run on the HTTP protocol. HTTP is an asymmetrical request-response protocol. The client sends a request message to the server, and the server returns a response message as illustrated in the figure below [2].

\subsection{Apache Tomcat Server}

According to [3] Apache Tomcat (or simply Tomcat, formerly also Jakarta Tomcat) is an open source web server and servlet container developed by the Apache Software Foundation(ASF). Tomcat implements the Java Servlet and the Java Server Pages (JSP) specifications from Sun Microsystems, and provides a "pure Java" HTTP web server environment for Java code to run in.

\subsection{SQL Database}

In this project, SQL is used as the backend database. Microsoft SQL server is a database server developed by the Microsoft Corporation. It is mainly used to fetch the data requested by any other software from the data stored in the server itself. The software which requests the data from the server could be on the same computer or either could be located away on a different computer connected remotely via the internet [4].

Microsoft SQL is designed to help with the workload of a wide range of audiences from small application based organization to large and vast data processing organizations which have a number of computer units to retrieve and access the data on servers. SQL database is connected to myeclipse using a JDBC driver. JDBC is a Java-based data access technology (Java Standard Edition platform) from Oracle Corporation, this technology is an API for the Java programming language that defines how a client may access a database [6]. It provides methods for querying and updating data in a database. JDBC is oriented towards relational databases. A JDBC-to-ODBC bridge enables connections to any ODBC-accessible data source in the JVM host environment [6].

\subsection{Existing System}

The existing system is usually paper based, when a new student get admission into the university he/she will go to the academic office to be screened and collects his admission letter. The screening method involves authenticating all the student credentials, after a successful screening the student will be given the following: course registration form (CRF), student information form (SIF), bank payment schedule and his admission letter. The student will then proceed to the bank and pays the specific amount applicable to his course, after successful payment the student will proceed to his department and copy the courses for that particular session after filling in the forms, he/she will proceed to each department he/she has a course to partake and get the signature of each level coordinator there after that then he/she can submit his registration details to his level coordinator.

\subsection{Propose System}

The objective of this paper is to develop a general purpose application that will address all these problems by providing a web based platform where schools can keep records about their school and the students. Furthermore, been a web based application means it can be accessible from anywhere at any time with minimum requirement (internet connection) both student and staffs can login into this secured platform and access information base on their profile.

The propose system is divided into two (2) modules, The master module and the MIS (management information system) report generation system module. The master module will handle all details about a student which include school details, courses details, student personal details, academic details e.t.c. while the MIS module will handle report generation system for the management.

\section{Our Contribution}

In order to design this web based application, the relational database is designed first. The design can be divided into two parts: The data model and the process model. The data model focuses on what data should be stored in the database while the Process model deals with how the data is processed. To put this in the 
context of the relational database, the data model is used to design the relational tables. The process model is used to design the queries that will access and perform operations on those tables.

\subsection{Data Model}

A data model is a conceptual representation of the data structures that are required by a database. The first step in designing of this database is the development of an Entity-Relation Diagram (ERD). The ERD serves as a blue print from which a relational database maybe deduced. Figure 1 below shows the ERD for the project and later we will show the transformation from ERD to the Relational model

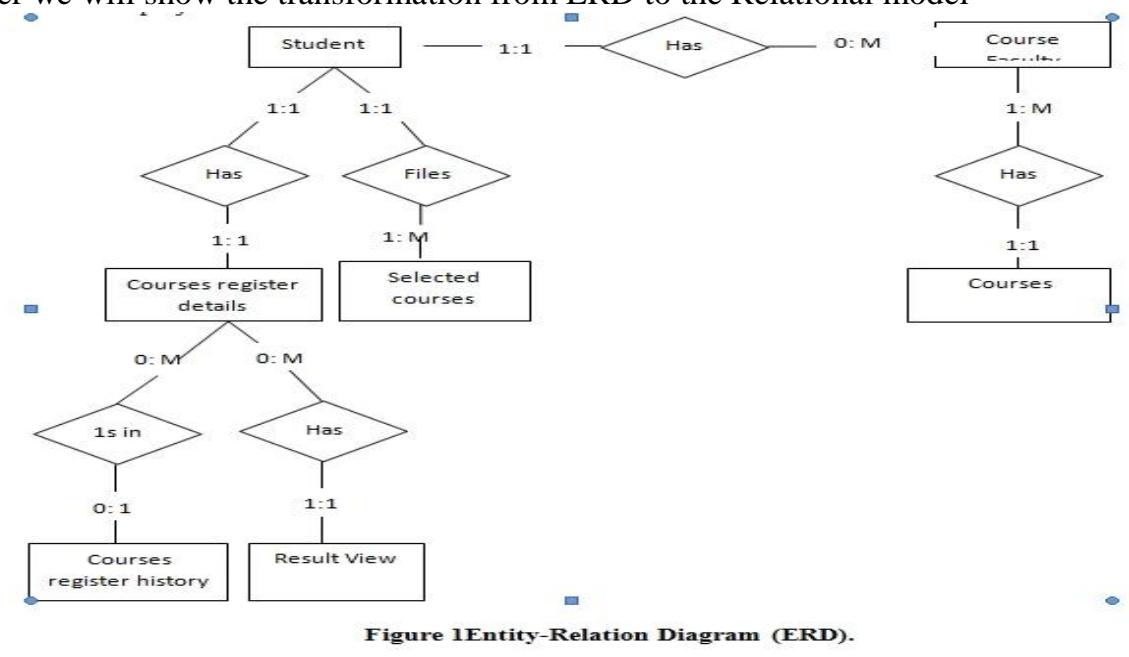

Entity A matches exactly one record in entity B and every record in B matches exactly one record in A. One to many means that every record in A matches zero or more records in B and every record in B matches exactly one record in A. If there is a one to many relationships between two entities, then these entities are represented as Associative Entities. In the Relational Database model, each of the entities will be transformed into a table. Some of the basics tables are shown below along with their attributes.

\subsubsection{Database Design}

In this section, the basic structure of the tables composing the database for the project are shown along with information about primary and foreign keys.

Student

\begin{tabular}{|c|c|c|c|}
\hline SNO & NAME & TYPE & DESCRIPTION \\
\hline 1 & StudentNo & Varchar & Primary key for Student identification \\
\hline 2 & firstname & Varchar & \\
\hline 3 & surname & Varchar & \\
\hline 4 & othername & Varchar & Security for Student \\
\hline 5 & gender & Varchar & \\
\hline 6 & dob & Varchar & \\
\hline 8 & telephone & Varchar & \\
\hline 9 & programname & Varchar & \\
\hline 10 & programcode & Varchar & \\
\hline 11 & grade & Varchar & \\
\hline 12 & address & Varchar & \\
\hline
\end{tabular}

Courses
\begin{tabular}{|c|c|c|c|}
\hline SNO & NAME & TYPE & DESCRIPTION \\
\hline 1 & id & Int & $\begin{array}{c}\text { Primary key for Courses } \\
\text { identification }\end{array}$ \\
\hline 2 & coursecode & varchar & \\
\hline 3 & coursename & varchar & \\
\hline 4 & credit & varchar & Foreign key to coursetype \\
\hline 5 & courseTypeId & Int & \\
\hline 7 & add_time & varchar & \\
\hline
\end{tabular}

Courses reg.
\begin{tabular}{|c|c|c|c|}
\hline SNO & NAME & TYPE & DESCRIPTION \\
\hline 1 & registerid & Int & $\begin{array}{c}\text { Primary key for course register } \\
\text { Identification }\end{array}$ \\
\hline 2 & StudentNo & varchar & Foreign key to Student \\
\hline
\end{tabular}


A B-S Model for Online Integrated Information System for Bayero University Kano Nigeria

\begin{tabular}{|c|c|c|c|}
\hline 3 & status & varchar & \\
\hline 4 & registerdate & datetime & \\
\hline \multicolumn{4}{|c|}{ Coursesregdetail } \\
\hline SNO & NAME & TYPE & DESCRIPTION \\
\hline 1 & registerid & varchar & Foreign key to coursereg \\
\hline 2 & courseid & varchar & Foreign key to Courses \\
\hline 3 & coursename & varchar & \\
\hline 4 & credit & varchar & \\
\hline \multicolumn{4}{|c|}{ Result } \\
\hline SNO & NAME & TYPE & DESCRIPTION \\
\hline 1 & StudentNo & varchar & Foreign key to Student \\
\hline 2 & courseid & Int & Foreign key to Courses \\
\hline 3 & Grade & varchar & \\
\hline 4 & registerid & Int & Foreign key to coursereg \\
\hline \multicolumn{4}{|c|}{ Admin } \\
\hline SNO & NAME & TYPE & DESCRIPTION \\
\hline 1 & Adminid & varchar & $\begin{array}{l}\text { Primary key for Admin } \\
\text { Identification }\end{array}$ \\
\hline 2 & un & varchar & \\
\hline 3 & pwd & varchar & \\
\hline 4 & realname & varchar & \\
\hline
\end{tabular}

\subsection{Process Model}

A Process Model deals with how data is processed and how data flows from one table to another to gather the required information. This model consists of the Functional Decomposition Diagram and Data Flow Diagram.

\subsubsection{Functional Decomposition Diagram}

A decomposition diagram shows a top-down functional decomposition of the system and exposes the system's structure. The objective of the Functional Decomposition is to break down the system step by step, beginning with the main function of a system and continuing with the interim levels down to the level of elementary functions. The diagram is the starting point for more detailed process diagrams, such as data flow diagrams (DFD). Figure 2 below shows the Functional Decomposition Diagram for this system.

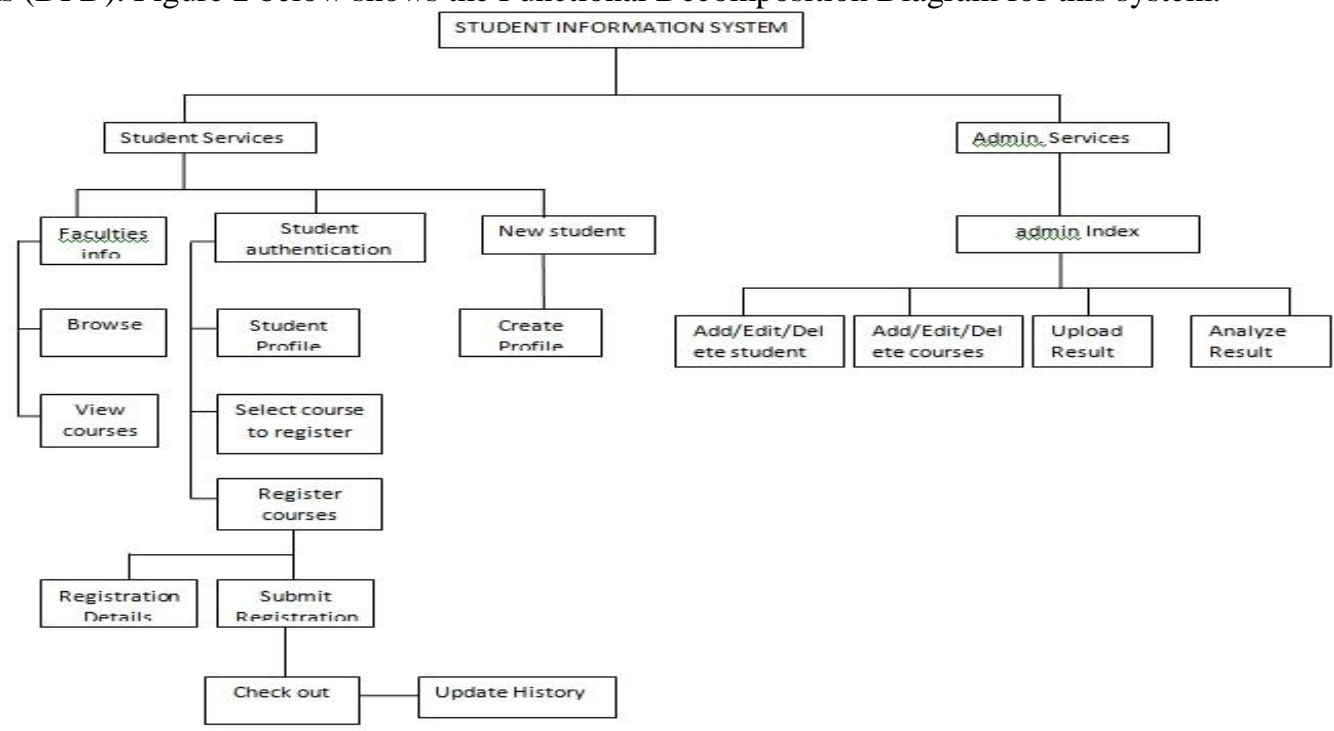

Figure 2 Functional Decomposition Diagram

\subsubsection{Data Flow Diagram (DFD)}

Data Flow Diagrams show the flow of data from external entities into the system, and from one process to another within the system. There are four symbols for drawing a DFD:

1. Rectangles representing external entities, which are sources or destinations of data.

2. Ellipses representing processes, which take data as input, validate and process it and output it.

3. Arrows representing the data flows, which can either, be electronic data or physical items. 
4. Open-ended rectangles or a Disk symbol representing data stores, including electronic stores such as databases or XML files and physical stores such as filing cabinets or stacks of paper.

Figures 3 -5 are the details Data Flow Diagrams for the current system.

$\underline{\text { Student-Browse Detailed DFD }}$

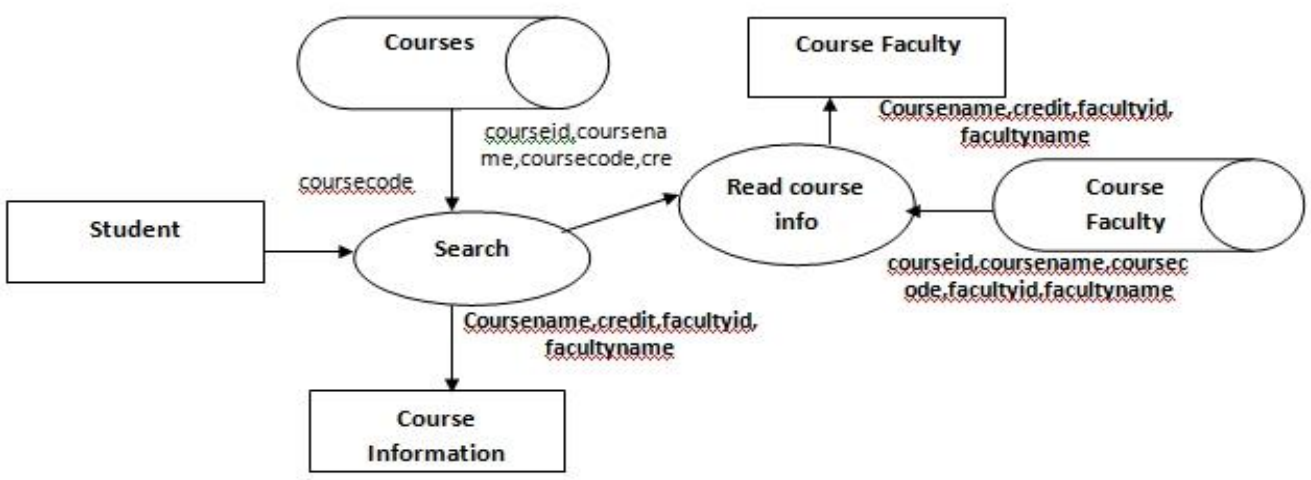

Figure 3 Student-Browse Detailed DFD

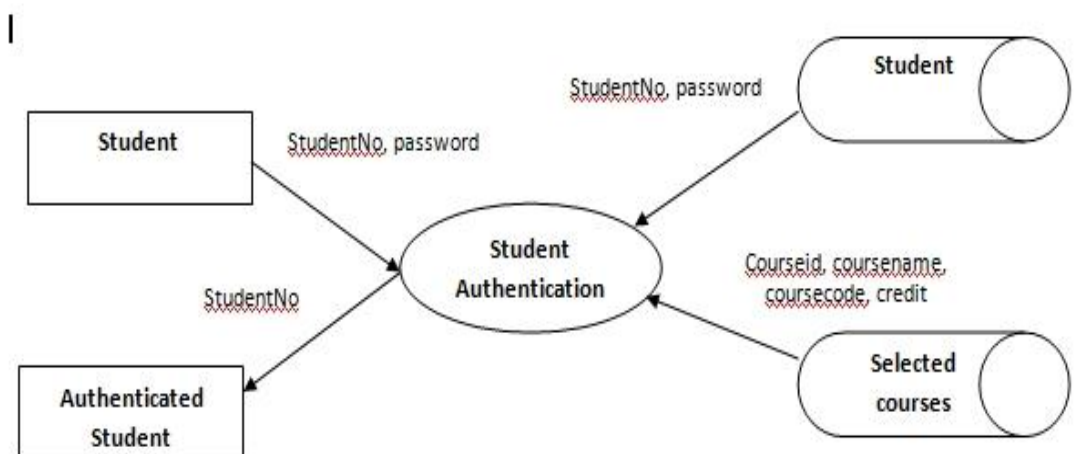

Figure 4 Student-Authentication Context DFD

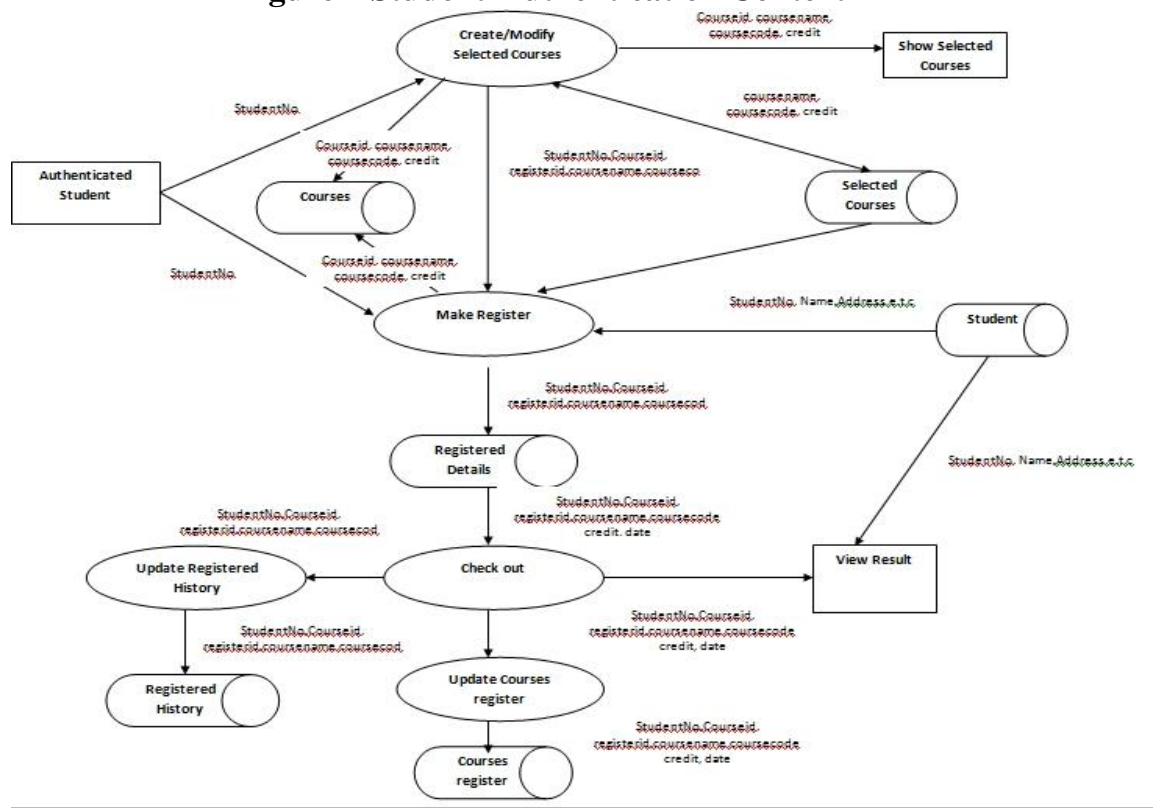

Figure 5 Authenticated Student-Register and Result Viewing DFD

\subsection{Implementation Technologies}

When the user types in the URL of the site in the address field of the browser, a web server is contacted to get the required information. The sole task of a web server is to accept incoming HTTP requests and to return 
the requested resources in an HTTP response [1].The web server needs a JSP engine i.e. container to process JSP pages, the JSP container is responsible for intercepting request for JSP pages. Apache Tomcat acts as the web server which has a built-in JSP container to support JSP pages developed [2]. Following diagram shows the position of JSP container and JSP files in a Web application.

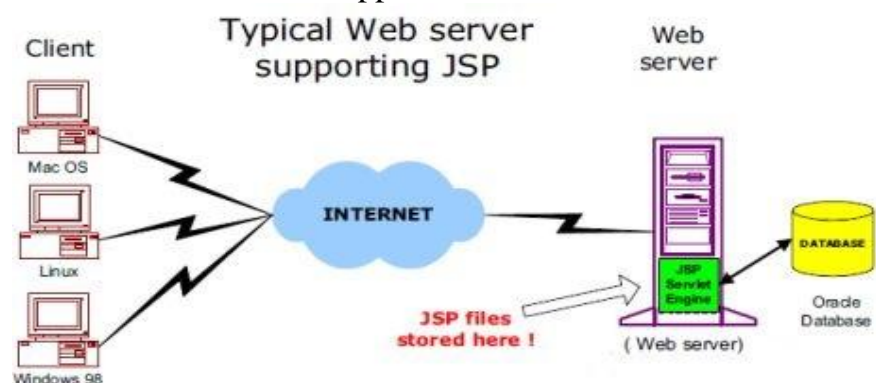

Figure 7: A Typical Web server supporting JSP

\title{
IV. Result Discussion
}

The objective of this application is to provide the student with an online application where they can register their courses from the comfort of their homes. The student can select the courses that he/she will take in the session, place them in the selected courses cart and register them. The student can print his registration details and at the end of the semester he/she can view and print his result.

Below figures show some screenshots taken from running the applications. All the functions are explained accordingly. When the user types the web address in the browser, the main page of the application is displayed, the student can browse through each faculty to see the courses available but at this point he/she can't register for a course without login.

\subsection{Student Registration}

A new student can register on the site by clicking on the register link on the menu at the top of the page. As shown in figure 7

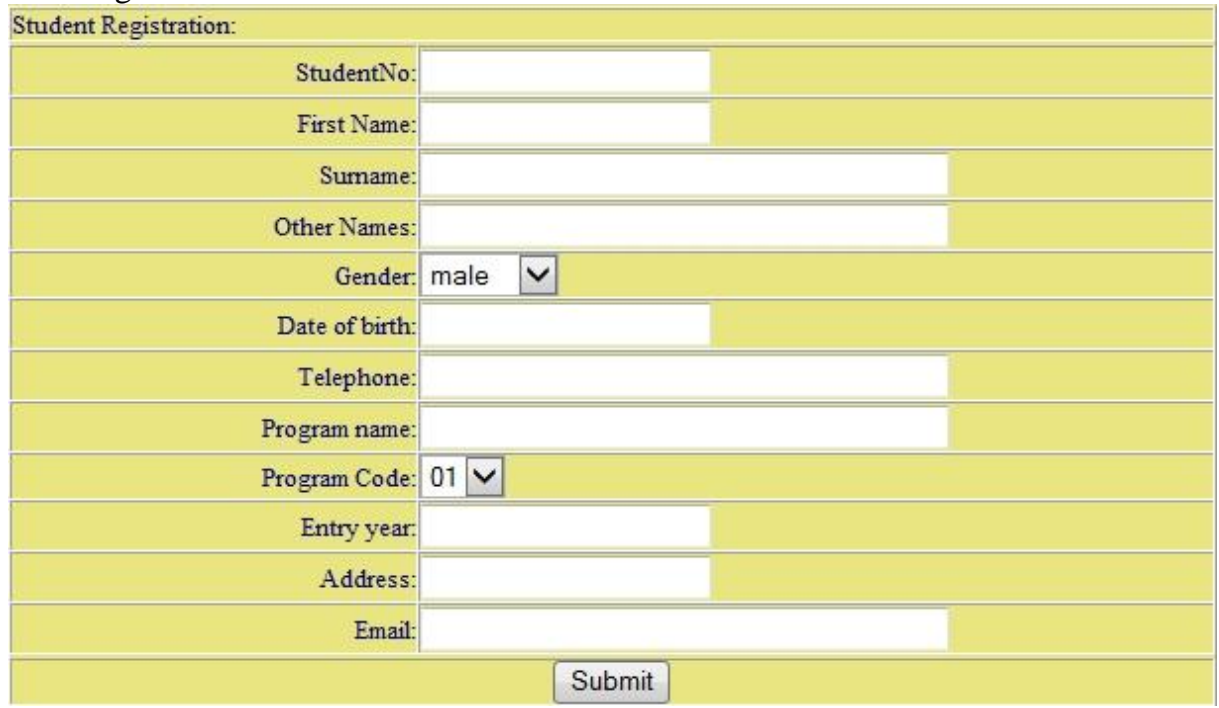

\subsection{Student Login}

Figure 7 New Student Registration

After the student supplied his student number and password then he/she can now perform three basic operations which are:

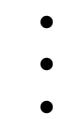

\author{
Courses Registration \\ View and print his semester Result
}

View his lectures schedules 


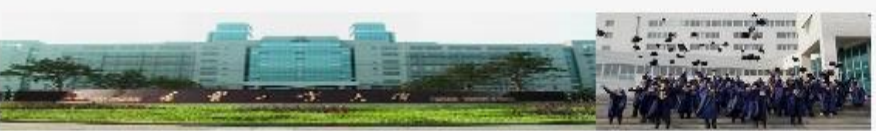

Home Management Register

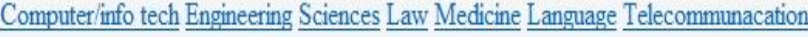

WelCome!SCI $05 /$ COM/03274
$\frac{\text { view courses you select }}{\text { view your Registered Courses }}$
$\frac{\text { view your result }}{\text { view time table }}$
Register Exit

\author{
Student Information System \\ a.Allightsreserved@ \\ Authorgezawa Email:gezawa@gmail.com
}

\title{
4.3 Selected Courses Cart
}

Figure 8 after a Student Login

When a student click on the link "click to register" for any course, it is added to the selected courses cart illustrated in figure 9 .

\begin{tabular}{|c|c|c|c|c|c|c|c|}
\hline \multicolumn{8}{|c|}{ Computer/info tech Engineering $\underline{\text { Home }} \underline{\text { Sciences Lawagement }} \underline{\underline{\text { Megister }}} \underline{\underline{\text { Medicine }}} \underline{\text { Language }} \underline{\text { Telecommunacation }}$} \\
\hline \multirow{11}{*}{$\begin{array}{l}\text { WelCome!SCI } / 05 / \mathrm{COM} / \mathrm{O} 3274 \\
\text { view courses you select } \\
\text { view your Registered Courses } \\
\frac{\text { view your result }}{\frac{\text { view time table }}{\text { Register Exit }}}\end{array}$} & No & Coursecode & Coursename & Count & credit unit & Totalcredit unit & delete \\
\hline & 1 & LNG3321 & CHINESE CUL TURE & 1 & . & 3.0 & delete \\
\hline & 2 & LNG2220 & EUROPEAN LANGUAGES & 1 & - & 2.0 & delete \\
\hline & 3 & TEL 3220 & INTERNET OF THINGS & 1 & . & 2.0 & delete \\
\hline & 4 & TEC5311 & MATERIAL DESIGN & 1 & . & 3.0 & delete \\
\hline & 5 & IEC2230 & MOBLE DESIGN & 1 & . & 2.0 & delete \\
\hline & 6 & CSC 3320 & TCP/IP PROTOCOLS & 1 & . & 3.0 & delete \\
\hline & 7 & CSC3320 & JAVA & 1 & E. & 3.0 & delete \\
\hline & 8 & $\operatorname{CSC} 2320$ & PROGRAMING IN C++ & 1 & . & 3.0 & delete \\
\hline & Sum & & & 8 & & 21.0 & \\
\hline & \multicolumn{7}{|c|}{ Make Register } \\
\hline & & & $\begin{array}{l}\text { Student Information Systen } \\
\text { @.Allrightsreserved@ }\end{array}$ & & & & \\
\hline & & Auth & 1or.gezawa Email:gezawa@gn & & & & \\
\hline
\end{tabular}

\section{Figure 9 Selected Course cart}

\subsection{Registering Courses}

When the "make register" button is clicked which is located on the button of the cart, the application will ask the student to confirm his registration or to "cancel" it as shown in the figure below.

\begin{tabular}{|c|c|c|c|c|c|}
\hline \multicolumn{6}{|c|}{ Student No :SCI/05/COM/O3274 } \\
\hline \multicolumn{6}{|c|}{ Surname : 01} \\
\hline \multicolumn{6}{|c|}{$\begin{array}{l}\text { Program code : } 04 \\
\text { Entry Year : } 2011\end{array}$} \\
\hline \multicolumn{6}{|c|}{ Register NO:48 Register Status:0 } \\
\hline No & Coursecode & CourseName & Count & credit unit & credit unit \\
\hline 1 & LNG3321 & CHINESE CULTURE & 1 & 3.0 & 3.0 \\
\hline 2 & LNG2220 & EUROPEAN LANGUAGES & 1 & 2.0 & 2.0 \\
\hline 3 & TEL 3220 & INTERNET OF THINGS & 1 & 2.0 & 2.0 \\
\hline 4 & IEC5311 & MATERIAL DESIGN & 1 & 3.0 & 3.0 \\
\hline 5 & $\operatorname{CSC} 3320$ & TCP/P PROTOCOLS & 1 & 3.0 & 3.0 \\
\hline 6 & $\overline{\text { TEC2230 }}$ & MOBILE DESIGN & 1 & 2.0 & 2.0 \\
\hline 7 & $\mathrm{CSC} 3320$ & JAVA & 1 & 3.0 & 3.0 \\
\hline 8 & $\overline{\operatorname{CSC} 2320}$ & PROGRAMING IN C + & 1 & 3.0 & 3.0 \\
\hline SUM & & & 8 & & 21.0 \\
\hline \multicolumn{6}{|c|}{ cancel register firm Register } \\
\hline
\end{tabular}

Figure 10 Course Registration 
When the student confirms the registration then the student can now view and print his registration details as shown in the figure below.

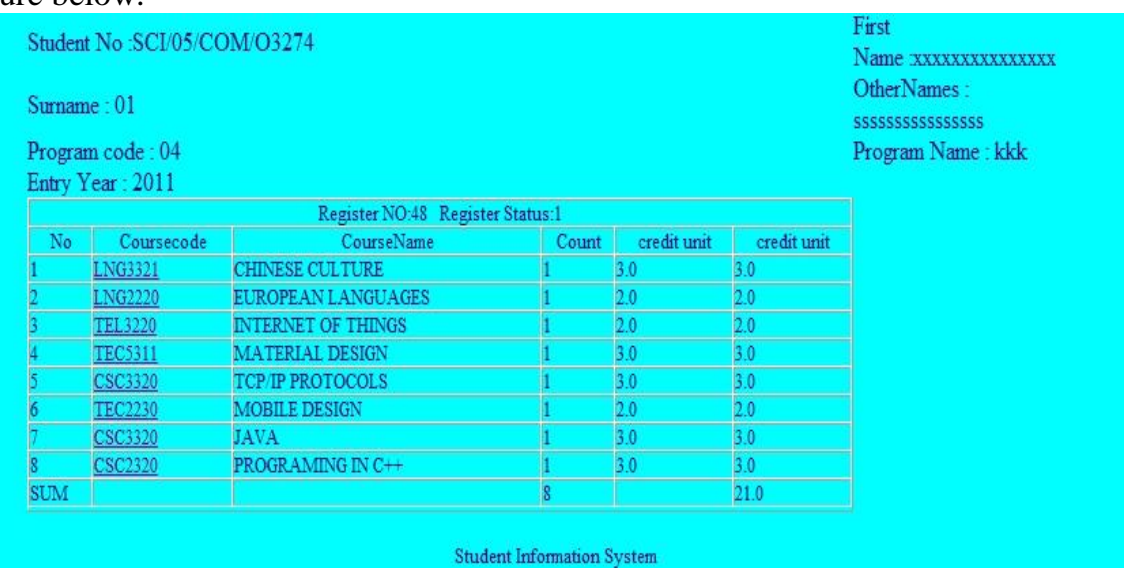

Figure 11 Student Course Registration Details

\subsection{Student End of Semester Result View}

If the end of semester result is available the student can click on the link "view semester Result" located in the menu bar and view his result as shown in the figure

\begin{tabular}{|c|c|c|c|c|c|c|c|c|}
\hline \multicolumn{8}{|c|}{ Student No :SCI/05/COM/O3274 } & $\begin{array}{l}\text { First } \\
\text { Name } x x x x x x x x x x x x x x x x\end{array}$ \\
\hline \multicolumn{8}{|c|}{ Surname : 01} & $\begin{array}{l}\text { OtherNames: } \\
\text { ssssssssssssssss }\end{array}$ \\
\hline \multicolumn{8}{|c|}{ Program code : 04} & Program Name : kkk \\
\hline \multicolumn{8}{|c|}{ Entry Year : 2011} & \\
\hline \multicolumn{8}{|c|}{ Register NO:48 Register Status:1 } & \\
\hline No & Coursecode & CourseName & Credit & Score & Grade & point & GP & \\
\hline 1 & LNG3321 & CHINESE CUL TURE & 3.0 & 60 & C & 3 & 9 & \\
\hline 2 & LNG2220 & EUROPEAN LANGUAGES & 2.0 & 65 & C & 3 & 6 & \\
\hline 3 & TEL 3220 & INTERNET OF THINGS & 2.0 & \$8 & B & 4 & 8 & \\
\hline 4 & TEC5311 & MATERIAL DESIGN & 3.0 & 95 & A & 5 & 15 & \\
\hline 5 & $\csc 3320$ & TCP/IP PROTOCOLS & 3.0 & 98 & A & 5 & 15 & \\
\hline 6 & TEC2230 & MOBILE DESIGN & 2.0 & 75 & B & 4 & 8 & \\
\hline 7 & $\operatorname{CsC} 3320$ & JAVA & 3.0 & 70 & B & 4 & 12 & \\
\hline 8 & $\operatorname{CSC} 2320$ & PROGRAMING IN C++ & 3.0 & 90 & A & 5 & 15 & \\
\hline Sum & & & 21.0 & & & & 88.0 & \\
\hline \multicolumn{8}{|c|}{ your CGPA is: 4.19} & \\
\hline \multicolumn{9}{|c|}{$\begin{array}{l}\text { Student Information System } \\
\text { @-Allightsreserved@ }\end{array}$} \\
\hline
\end{tabular}

\subsection{Administrator Roles}

Figure 12 Student End of semester Result View

Courses information can only be changed by the administrator of the site, the admin. Can also add, edit and delete courses information. The admin is also responsible for uploading student result and analyze the student performance.

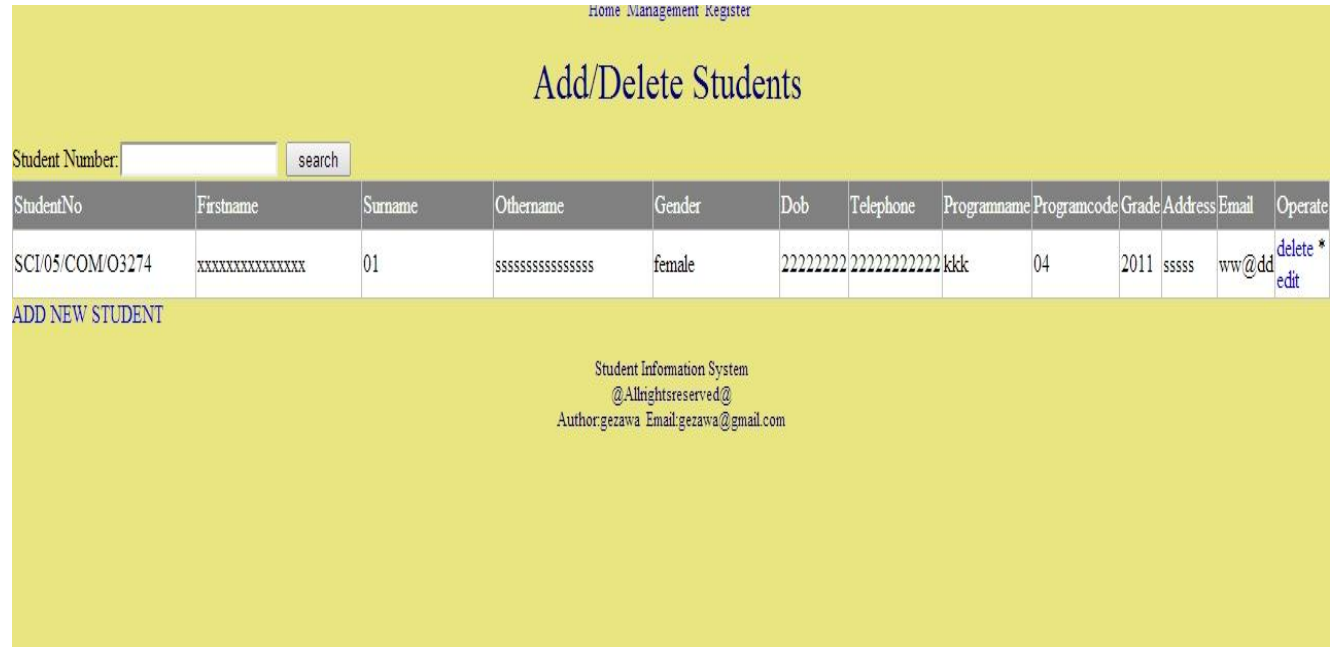

Figure 13 Admin Functions 


\begin{tabular}{l|l|l|l|l|l|l|l|l|}
\hline \multicolumn{2}{c}{ Add/Delete Courses } & & & & & \\
\hline
\end{tabular}

Figure 14 Admin Functions

\section{Conclusion}

The internet has become a major resources in our lives, thus information technology in educational management has gained significance not only from the management but also from the students point of view. We have successfully designed and implemented A B-S Model for Online Integrated Information System for Bayero University Kano Nigeria, the future work to be carried-out is online student result evaluations analysis, with this future work the system will be a full fledge system.

\section{References}

[1]. Visscher, A. J. (1991). School administrative computing: A framework for analysis. Journal of Research on Computingin Education, 24(1), 1-19.

[2]. A Servlet and JSP tutorial URL: http://www.apl.jhu.edu/ hall/java/Servlet-Tutorial/

[3]. http://en.wikipedia.org/wiki/Apache_Tomcat

[4]. http://wooservers.com/blog/2011/12/27/what-is-microsoft-sql-server/

[5]. http://en.wikipedia.org/wiki/Java_Database_Connectivity

[6]. Sun Microsystems, Java URL: http://java.sun.com/

[7]. Visscher, A. J., Spuck, D. W., \& Bozeman, W. C. (Eds.) (1991). Computer-assisted school administration and management: The state of the art in seven nations. Journal of Research on Computing in Education, 24(1), 1-168.

[8]. Nolan, P., \& Visscher, A. J. (1996). Research on application on information technology in educational management. In J.

D. Tinsley \& T. J. van Weert (Eds.), Post-conference Report on the Sixth IFIP World Conference on Computers in Education (pp. 163-168). Birmingham: 1FIP Technical Committee 3

[9]. Visscher, A. I. (1990). The computer as management tool: Promises and pitfalls. In A. McDougall \& C. Dowling (Eds.), Proceedings of The Fifth World Conference on Computers in Education (pp. 609-614). Amsterdam: Elsevier Science Publisher B. V

[10]. http://www.netsity.com/webbasedapplication.htm

[11]. Norman, D. A. (2000). The Rise of Weblications: Keynote address presented at the User Experience World Tour. November 17, 2000, Chicago. IL.

[12]. Nail, J. (1998). Why did we choose the 'weblication' route. ZDNet Anchor Desk, http://www.zdnet.com/anchordesk/talkback/talkback 93309.html

[13]. Brown, S., Burdick, R., Falkner, J., Galbraith, B., Johnson, R., Kim, L., Kochmer,

[14]. C., Kristmundsson, T. and Li S (2001). Professional JSP. Wrox Press Ltd.

[15]. http://en.wikipedia.org/wiki/Apache_Tomcat

[16]. http://www.tutorialspoint.com/jsp/jsp architecture.htm

[17]. http://www3.ntu.edu.sg/home/ehchua/programming/java/javaservlets.html

[18]. http://www.mulesoft.com/tcat/tomcat-servlet

[19]. http://wooservers.com/blog/2011/12/27/what-is-microsoft-sql-server/ 